\title{
ZnO Nanocrystals as Anode Electrodes for Lithium-Ion Batteries
}

\author{
Wenhui Zhang, ${ }^{1}$ Lijuan Du, ${ }^{1}$ Zongren Chen, ${ }^{1}$ Juan Hong, ${ }^{2}$ and Lu Yue ${ }^{1}$ \\ ${ }^{1}$ Jiangsu Collaborative Innovation Center for Ecological Building Materials and Environmental Protection Equipments, Key Laboratory \\ for Advanced Technology in Environmental Protection of Jiangsu Province, Yancheng Institute of Technology, Yancheng 224051, China \\ ${ }^{2}$ College of Mechanical Engineering, Yancheng Institute of Technology, Yancheng 224051, China
}

Correspondence should be addressed to Juan Hong; jameshong@ycit.cn and Lu Yue; yuelu66@126.com

Received 8 March 2016; Accepted 24 April 2016

Academic Editor: Gongming Wang

Copyright (C) 2016 Wenhui Zhang et al. This is an open access article distributed under the Creative Commons Attribution License, which permits unrestricted use, distribution, and reproduction in any medium, provided the original work is properly cited.

$\mathrm{ZnO}$ nanocrystals were synthesized via a thermal decomposition method. X-ray diffraction, transmission electron microscopy, and photoluminescence were used to investigate the composition and nanostructure of the material. Compared with commercial $\mathrm{ZnO}$ nanoparticles, $\mathrm{ZnO}$ nanocrystals showed higher lithium storage capacity and better cycling characteristics and exhibited a reversible discharge capacity of $500 \mathrm{mAh} \mathrm{g}^{-1}$ after 100 cycles at $200 \mathrm{~mA} \mathrm{~g}^{-1}$.

\section{Introduction}

Transition metal oxides have gained more and more interest as electrode materials in lithium-ion batteries in the last decades because of their higher theoretical capacity and safety compared with the conventional carbon materials [1-4]. Among them, $\mathrm{ZnO}$, a wide-bandgap semiconductor of $3.37 \mathrm{eV}$ at room temperature with large exciton binding energy of $60 \mathrm{meV}$, is a multifunctional material for a variety of practical applications such as piezoelectric devices [5], field emission [6], gas sensors [7], dye-sensitized solar cells [8], and photocatalysts [9] due to its excellent physical and chemical properties. $\mathrm{ZnO}$ has superior advantages such as low cost, facile preparation, morphologic diversity, and high chemical stability. $\mathrm{ZnO}$ nanocrystals with different morphologies have some special properties of physics, so intense interests have been devoted to the synthesis of $\mathrm{ZnO}$ with various morphologies such as nanowires [10], nanobelts [11], nanorods [12], and nanosheets [13].

As an anode material of lithium-ion batteries, $\mathrm{ZnO}$ has a theoretical capacity of $978 \mathrm{mAhg}^{-1}$ [14]. However, the poor electronic conductivity, large volume change during lithium/delithium process, and the resulting severe capacity fading hinder its practical application [15]. Hitherto, some efforts have been made to improve its cycling performance including synthesis of nanostructures [15-17], doping and forming composite with metal $[18,19]$, metal oxide $[20-$ $22]$, carbon $[23,24]$, and graphene [25, 26]. For example, dandelion-like $\mathrm{ZnO}$ nanorod arrays showed higher lithium storage capacity and better cycling characteristics compared to powder-form $\mathrm{ZnO}$ [27]. Mesoporous $\mathrm{ZnO}$ nanosheets exhibit a 50th charge capacity of $420 \mathrm{mAh} \mathrm{g}^{-1}$, and the capacity and cycling performance are enhanced compared with those of common solid $\mathrm{ZnO}$ particles [17]. More significant research efforts are needed to further improve the lithiumion battery performances of $\mathrm{ZnO}$.

In the present work, $\mathrm{ZnO}$ nanocrystals have been prepared by a thermal decomposition method and their electrochemical performances as lithium anode materials are investigated.

\section{Experimental Section}

2.1. Preparation of $\mathrm{ZnO}$ Nanocrystals. $0.316 \mathrm{~g}$ zinc stearate $\left(\mathrm{Zn}(\mathrm{St})_{2}, 10-12 \% \mathrm{Zn}\right.$ basis, Sigma-Aldrich) and $10 \mathrm{~g} \mathrm{1-}$ octadecene (ODE, technical grade, 90\%, Sigma-Aldrich) were loaded in a $50 \mathrm{~mL}$ three-necked flask, degassed, and heated to $270^{\circ} \mathrm{C}$ under an argon flow. A separate solution of $2.5 \mathrm{~g}$ ODE containing $0.676 \mathrm{~g}$ 1-octadecanol (ODA, 95\%, Sigma-Aldrich) at $200^{\circ} \mathrm{C}$ was rapidly injected into the reaction flask to generate nanocrystals. The reaction was allowed 
to proceed for $30 \mathrm{~min}$. When the reaction was finished, the reaction mixture was cooled to room temperature. The resulting nanocrystals were precipitated out by adding ethyl acetate, carefully purified with hexane/ethanol mixtures, and dried at $70^{\circ} \mathrm{C}$. Ethyl acetate (AR), hexane (AR), and ethanol (AR) were purchased from Sinopharm Chemical Reagent Co. Commercial $\mathrm{ZnO}$ nanoparticles $(30 \pm 10 \mathrm{~nm})$ were purchased from Aladdin Industrial Corporation for comparison.

2.2. Characterization of $\mathrm{ZnO}$ Nanocrystals. Powder X-ray diffraction (XRD) analyses were performed on a Philips PW$1830 \mathrm{X}$-ray diffractometer with $\mathrm{Cu} \mathrm{K} \alpha$ irradiation $(\lambda=$ $1.5406 \AA$ ) at a scanning speed of $0.014^{\circ} / \mathrm{sec}$ over the $2 \theta$ range of $30-60^{\circ}$. The electronic morphology of the samples was examined by a transmission electron microscope (TEM; FEI Tecnai G2 Spirit, USA). Photoluminescence (PL) spectra of the sample on Si substrate were recorded using Jobin-Yvon LabRAM high-resolution spectrometer with $\mathrm{He}-\mathrm{Cd}$ laser $(\lambda=325 \mathrm{~nm})$. Cyclic voltammetry $(\mathrm{CV})$ and electrochemical impedance spectroscopy (EIS) results were obtained with Zennium/IM6 electrochemical workstation (Zahner, Germany).

2.3. Electrochemical Performance. The coin cells (CR2025) were assembled to test the electrochemical performance of the as-prepared electrodes. The as-prepared samples were mixed with acetylene black and carboxymethyl cellulose, in a weight ratio of $60: 20: 20$ in an aqueous solution to form homogeneous slurry. The slurry was spread onto $10 \mu \mathrm{m}$ thick copper foil and dried at $60^{\circ} \mathrm{C}$ for $12 \mathrm{~h}$ in a vacuum oven and then pressed to obtain the electrode sheet with a $9-10 \mu \mathrm{m}$ coating thickness and a loading level of about $1.4 \mathrm{mg} \mathrm{cm}^{-2}$. The electrolyte of $1 \mathrm{M} \mathrm{LiPF}_{6}$ and $5 \%$ fluoroethylene carbonate (FEC) in ethylene carbonate (EC, >99.9\%)/diethylene carbonate (DEC, >99.9\%)/dimethyl carbonate (DMC, >99.9\%) $(\mathrm{v}: \mathrm{v}: \mathrm{v}=1: 1: 1$, water content $<20 \mathrm{ppm})$ was purchased from Zhangjiagang Guotai-Huarong New Chemical Materials Company (China). The cells were assembled in an Ar filled glove-box. The cells were charged and discharged galvanostatically in the fixed voltage window from $0.01 \mathrm{~V}$ to $3 \mathrm{~V}$ on a Shenzhen Neware battery cycler (China) at $25^{\circ} \mathrm{C}$.

EIS was measured by applying an alternating voltage of $5 \mathrm{mV}$ over the frequency ranging from $10^{-2}$ to $10^{5} \mathrm{~Hz}$. In this work, unless otherwise specified, all impedance measurements were carried out after one cycle of the prepared electrode.

\section{Results and Discussion}

The crystal structure of the sample was characterized by XRD, as shown in Figure 1. All diffraction peaks can be indexed as the hexagonal phase of $\mathrm{ZnO}$, which is in good agreement with JCPDS number 36-1451.

The typical morphology of $\mathrm{ZnO}$ nanocrystals and commercial $\mathrm{ZnO}$ nanoparticles, as observed by TEM, is presented in Figure 2. It can be seen that the reaction generated trigonal $\mathrm{ZnO}$ nanocrystals with the size of $10-15 \mathrm{~nm}$ (side-edge length). The diameter of commercial $\mathrm{ZnO}$ nanoparticles was $30 \pm 10 \mathrm{~nm}$.

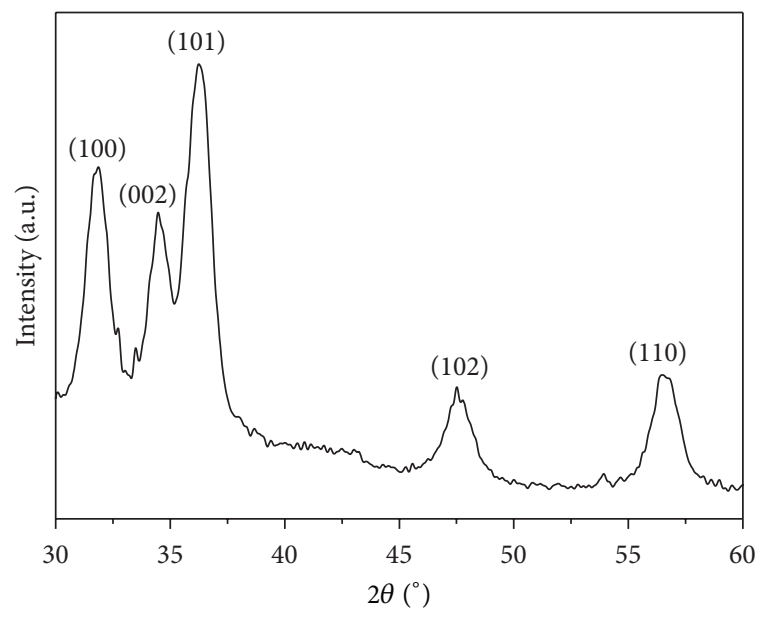

FIGURE 1: XRD pattern of $\mathrm{ZnO}$ nanocrystals.

PL spectrum of the sample is shown in Figure 3. Strong excitonic emission at $375 \mathrm{~nm}$ and a broad but weak spectral band ranging from 450 to $600 \mathrm{~nm}$ were observed. The nearUV peak is due to the recombination of electron and hole in an exciton, while the visible emission is due to the presence of various point defects, such as interstitial oxygen and oxygen vacancies.

The electrochemical properties of $\mathrm{ZnO}$ nanocrystal and commercial $\mathrm{ZnO}$ nanoparticle electrode for lithium-ion batteries were investigated. Figure 4 reveals the $\mathrm{CV}$ of the electrodes at a scan rate of $0.5 \mathrm{mV} \mathrm{s}^{-1}$ in the voltage ranging from 0.01 to $3 \mathrm{~V}$. Both of the first discharge process (negative scan) of $\mathrm{ZnO}$ nanocrystal and the commercial $\mathrm{ZnO}$ electrodes showed broad peaks around $1.2-1.0 \mathrm{~V}$ and $0.5-0.7 \mathrm{~V}$ and a sharp reduction peak below $0.3 \mathrm{~V}$, corresponding to the irreversible reactions (the reaction of FEC decomposition and formation of primal solid electrolyte interface (SEI) film on the surface of composite electrode) and the insertion of $\mathrm{Li}$ ions into $\mathrm{ZnO}$, respectively. The relative peak at $0.5 \mathrm{~V}$ originated from the reduction of $\mathrm{ZnO}$ into $\mathrm{Zn}$ and the formation of amorphous $\mathrm{Li}_{2} \mathrm{O}$, while the strong peak near $0.25 \mathrm{~V}$ was caused by the generation of $\mathrm{Li}-\mathrm{Zn}$ alloy together with the decomposition of electrolyte. These peaks disappeared in further cycles, indicating the irreversible reduction of $\mathrm{ZnO}$ with a large irreversible capacity in the first cycle. New reduction peaks at about 0.80 and $0.30 \mathrm{~V}$ appeared after the first cycle and shifted to a lower voltage during further cycles. In the subsequent delithium process for $\mathrm{ZnO}$ nanocrystals (Figure $4(\mathrm{a})$ ), six weak oxidation peaks centred at $0.27,0.52,0.63$, $1.48,1.78$, and $2.20 \mathrm{~V}$ could be carefully discerned which could be attributed to multistep dealloying of Li- $\mathrm{Zn}$ alloy. However, for commercial $\mathrm{ZnO}$ electrode (Figure 4(b)), only two oxidation peaks of 0.65 and $1.52 \mathrm{~V}$ could be found in the CV curves. Besides, the $\mathrm{ZnO}$ nanocrystal electrode displayed a higher peak current in both oxidation-reduction reaction processes, indicating that a better and more active electrode reaction happened.

The cycling performances of $\mathrm{ZnO}$ nanocrystal and commercial $\mathrm{ZnO}$ nanoparticle electrode at a current density 


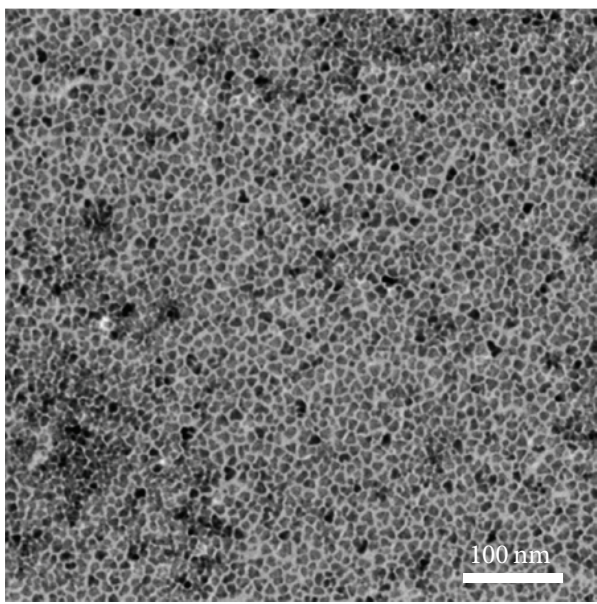

(a)

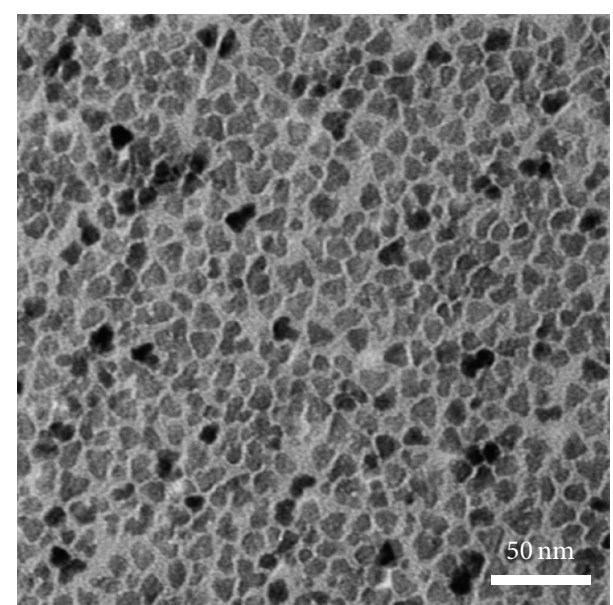

(b)

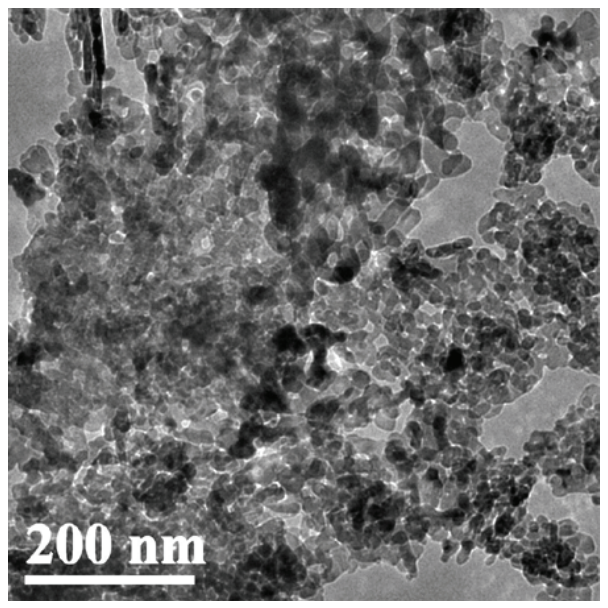

(c)

Figure 2: TEM images of (a, b) $\mathrm{ZnO}$ nanocrystals and (c) commercial $\mathrm{ZnO}$ nanoparticles.

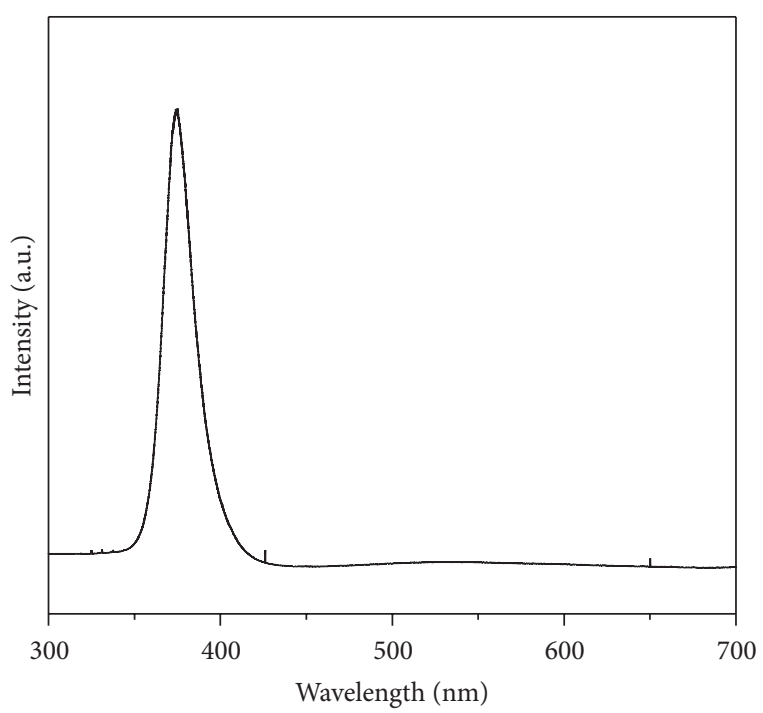

Figure 3: PL spectrum of $\mathrm{ZnO}$ nanocrystals. of $200 \mathrm{~mA} \mathrm{~g}^{-1}$ and $400 \mathrm{~mA} \mathrm{~g}^{-1}$ were displayed in Figure 5 . At $200 \mathrm{~mA} \mathrm{~g}^{-1}, \mathrm{ZnO}$ nanocrystal electrode delivered a high initial charge/discharge capacity of $709 / 1563 \mathrm{mAh} \mathrm{g}^{-1}$ and exhibited a high average discharge capacity of $500 \mathrm{mAh} \mathrm{g}^{-1}$ over 100 cycles, while commercial $\mathrm{ZnO}$ nanoparticle electrode delivered a lower initial charge/discharge capacity of 489/1273 $\mathrm{mAh} \mathrm{g}^{-1}$ and exhibited a lower average discharge capacity of $112 \mathrm{mAh} \mathrm{g}^{-1}$ over 100 cycles. At $400 \mathrm{~mA} \mathrm{~g}^{-1}$, the electrodes showed similar results. The $\mathrm{ZnO}$ nanocrystal electrode displayed a better cycling performance, which delivered an initial charge/discharge capacity of $676 / 1475 \mathrm{mAh} \mathrm{g}^{-1}$ with a coulombic efficiency of $45.8 \%$ and exhibited the discharge capacity of $428 \mathrm{mAh} \mathrm{g}^{-1}$ over 100 cycles.

The rate capabilities of $\mathrm{ZnO}$ nanocrystal electrode are shown in Figure 6. ZnO nanocrystal electrode was cycled at a current density of $200 \mathrm{~mA} \mathrm{~g}^{-1}$ for the initial 2 cycles. Then, the current density was increased gradually to $4000 \mathrm{~mA} \mathrm{~g}^{-1}$ and finally returned to $200 \mathrm{mAg}^{-1}$. The $\mathrm{ZnO}$ nanocrystal 


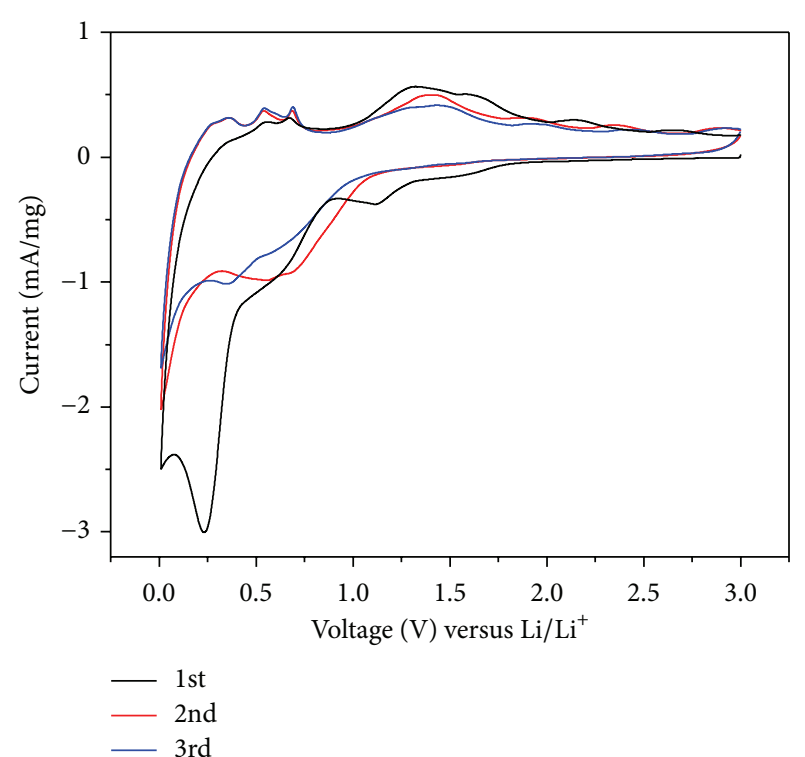

(a)

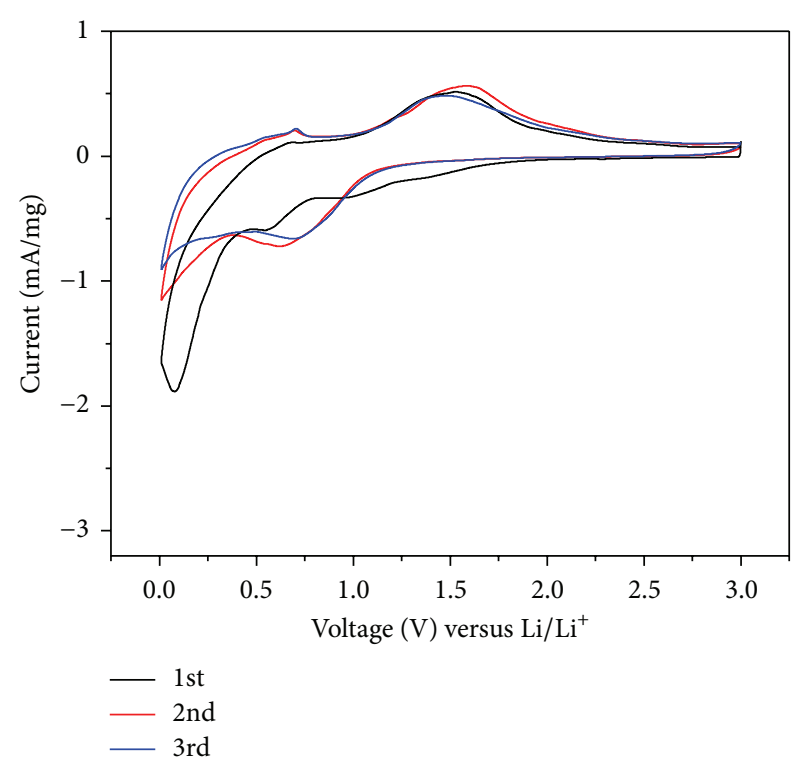

(b)

FIGURE 4: Cyclic voltammograms of (a) $\mathrm{ZnO}$ nanocrystal and (b) commercial $\mathrm{ZnO}$ nanoparticle electrode tested at $0.5 \mathrm{mV} \mathrm{s}^{-1}$ in $0.01-3 \mathrm{~V}$.

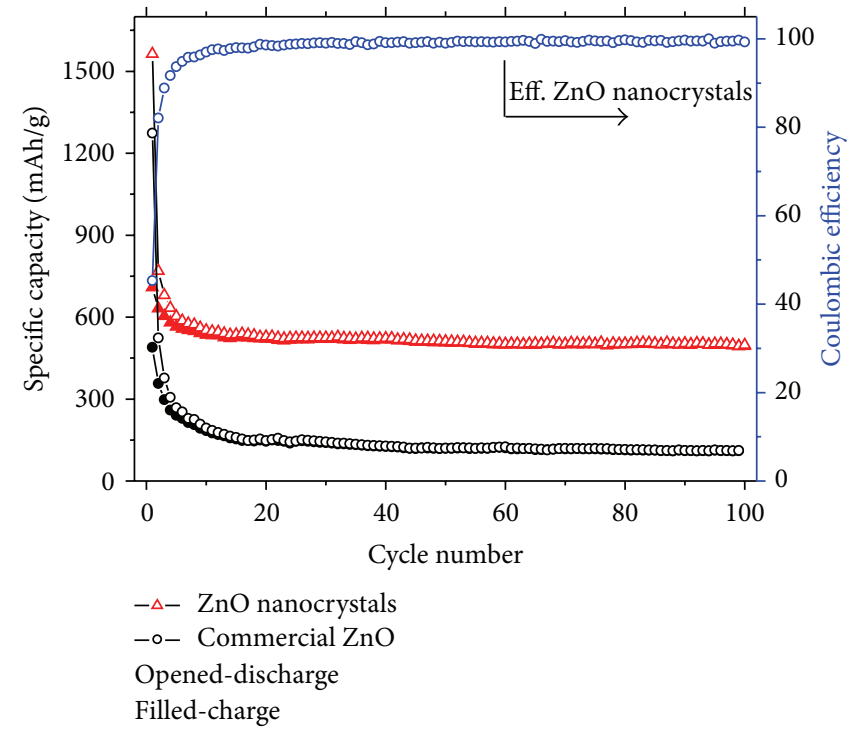

(a)

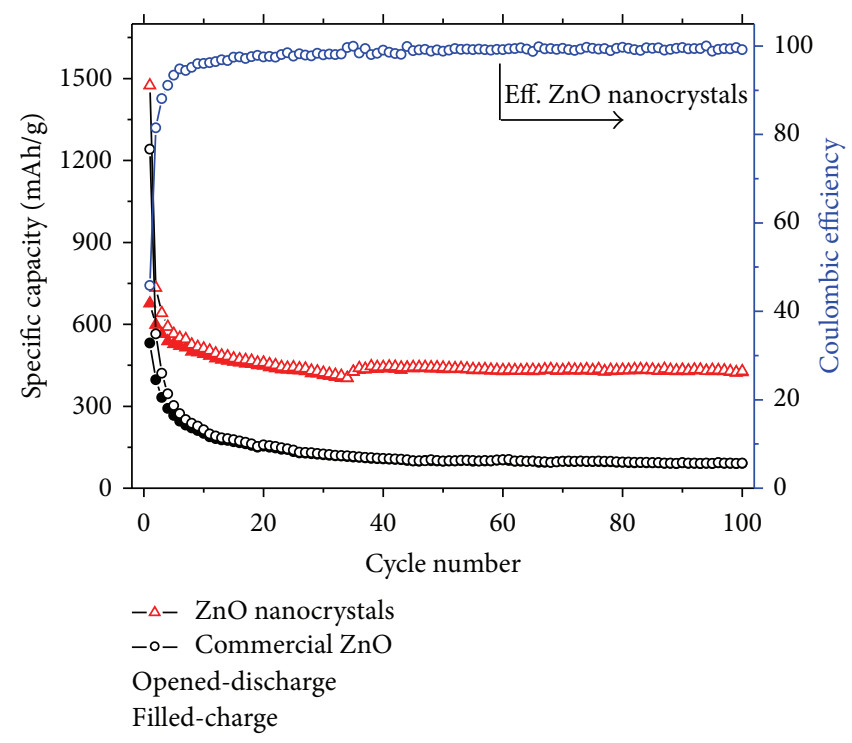

(b)

FIGURE 5: Cycle performances of $\mathrm{ZnO}$ nanocrystal and commercial $\mathrm{ZnO}$ nanoparticle electrode at a current density of (a) $200 \mathrm{mAg}^{-1}$ and (b) $400 \mathrm{~mA} \mathrm{~g}^{-1}$.

electrode showed a first charge/discharge capacity of 570/ $1272 \mathrm{mAhg}^{-1}$ with a coulombic efficiency of $44.8 \%$. At a higher current density of 500,1000,2000, 3000, and $4000 \mathrm{~mA} \mathrm{~g}^{-1}$, the capacity dropped to about $309,187,114,75$, and $51 \mathrm{mAh} \mathrm{g}^{-1}$, respectively.

To investigate the difference in electrochemical performance, EIS was employed to characterize the impedance properties of electrodes. The Nyquist complex plane impedance plots of the electrodes after the first two charge/discharge cyclic processes are presented in Figure 7. Both Nyquist plots which consisted of a depressed semicircle at high frequency range correlated with the electron transfer resistance on the interface of electrode/electrolyte. These Nyquist plots were fitted with the equivalent circuit (inset), as shown in Figure 7. This equivalent circuit consisted of a series of four resistors elements, three constant-phase elements (CPE), and a Warburg diffusion element. In the equivalent circuit, $R_{1}$ was composed of the electrolyte resistance $\left(R_{s}\right)$ and the electrode resistance $\left(R_{e}\right) ; R_{2}$ represented the SEI film resistances; $R_{3}$ represented the interphase electronic contacts 
TABLE 1

\begin{tabular}{|c|c|c|c|c|c|c|c|c|c|c|c|}
\hline \multirow{2}{*}{ Sample ID } & \multirow{2}{*}{$\begin{array}{c}R_{1} \\
(\Omega)\end{array}$} & \multirow{2}{*}{$\begin{array}{l}R_{2} \\
(\Omega)\end{array}$} & \multirow{2}{*}{$\begin{array}{l}R_{3} \\
(\Omega)\end{array}$} & \multirow{2}{*}{$\begin{array}{l}R_{4} \\
(\Omega)\end{array}$} & \multicolumn{2}{|c|}{$\mathrm{CPE}_{1}$} & \multicolumn{2}{|c|}{$\mathrm{CPE}_{2}$} & \multicolumn{2}{|c|}{$\mathrm{CPE}_{3}$} & \multirow{2}{*}{$\begin{array}{c}W \\
(\mathrm{DW})\end{array}$} \\
\hline & & & & & $\begin{array}{l}Y_{0,1} \\
(\mu \mathrm{F})\end{array}$ & $n$ & $\begin{array}{l}Y_{0,2} \\
(\mu \mathrm{F})\end{array}$ & $n$ & $\begin{array}{l}Y_{0,3} \\
(\mu \mathrm{F})\end{array}$ & $n$ & \\
\hline Commercial $\mathrm{ZnO}$ & 0.3 & 1.7 & 107.1 & 43.1 & 0.55 & 0.4 & 4.7 & 0.8 & 103.5 & 0.7 & 69.2 \\
\hline $\mathrm{ZnO}$ nanocrystals & 0.3 & 1.3 & 53.4 & 22.2 & 0.91 & 0.4 & 6.2 & 0.6 & 280.5 & 0.6 & 47.6 \\
\hline
\end{tabular}

$Y_{0}$ and $n$ are two parameters of the constant-phase element.

TABLE 2: Electrochemical performance comparison of $\mathrm{ZnO}$-based anodes for lithium-ion batteries.

\begin{tabular}{|c|c|c|c|c|}
\hline The structure of the material & Specific discharge capacity $\left(\mathrm{mAhg}^{-1}\right)$ & Cycle number & Current density & References \\
\hline $\mathrm{ZnO}$ radial hollow microparticles & 320 & 100 & $200 \mathrm{~mA} \mathrm{~g}^{-1}$ & [28] \\
\hline $\mathrm{ZnO}$ nanowires & 252 & 30 & $120 \mathrm{mAg}^{-1}$ & [29] \\
\hline $\mathrm{ZnO}$ flower-like microaggregates & 179 & 200 & $1 \mathrm{C}$ & {$[30]$} \\
\hline $\mathrm{ZnO}$ dandelion-like nanorod arrays & 310 & 40 & $250 \mathrm{~mA} \mathrm{~g}^{-1}$ & [27] \\
\hline $\mathrm{ZnO}$ flower-like arrays & 238 & 50 & $0.5 \mathrm{C}$ & {$[31]$} \\
\hline $\mathrm{ZnO}$ microrod arrays & 150 & 50 & $500 \mathrm{~mA} \mathrm{~g}^{-1}$ & [16] \\
\hline $\mathrm{ZnO}$ nanowire arrays & 200 & 40 & $120 \mathrm{~mA} \mathrm{~g}^{-1}$ & [32] \\
\hline $\mathrm{ZnO}$ flower-like microparticles & 200 & 50 & $120 \mathrm{~mA} \mathrm{~g}^{-1}$ & [33] \\
\hline $\mathrm{ZnO}$ nanoplates & 368 & 100 & $0.1 \mathrm{C}$ & [34] \\
\hline $\mathrm{ZnO}$ mesoporous nanosheets & 420 & 50 & $100 \mathrm{~mA} \mathrm{~g}^{-1}$ & [17] \\
\hline Flower-like $\mathrm{ZnO}$ nanospheres & 381 & 30 & $0.5 \mathrm{C}$ & [35] \\
\hline Ultralong mesoporous $\mathrm{ZnO}$ nanowires & 432 & 10 & $0.1 \mathrm{C}$ & {$[36]$} \\
\hline \multirow{2}{*}{$\mathrm{ZnO}$ nanocrystals } & 500 & \multirow{2}{*}{100} & $200 \mathrm{~mA} \mathrm{~g}^{-1}$ & \multirow{2}{*}{ This work } \\
\hline & 428 & & $400 \mathrm{~mA} \mathrm{~g}^{-1}$ & \\
\hline
\end{tabular}

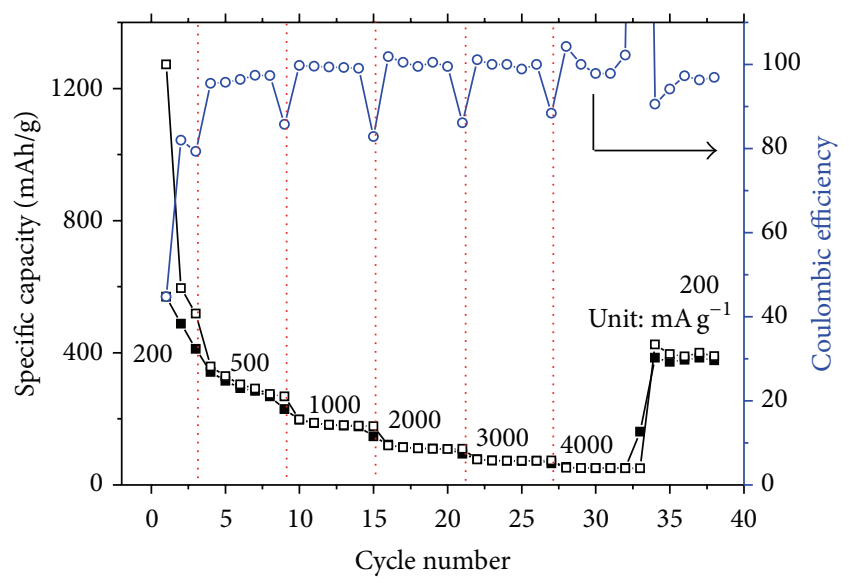

FIGURE 6: Rate performance of $\mathrm{ZnO}$ nanocrystal electrode.

resistance; $R_{4}$ was the charge-transfer resistance across electrode/electrolyte interface; $\mathrm{CPE}_{1}$ and $\mathrm{CPE}_{2}$ were attributed to the $\mathrm{Li}^{+}$diffusion in the SEI film and pore channel of the electrode materials, respectively; $\mathrm{CPE}_{3}$ represented the electric double-layer capacitance of electrode/solution interface; $Z_{W}$ which represented Warburg impedance was related to the semi-infinite diffusion of lithium ions into the bulk electrode [37, 38].

By fitting the impedance data, the typical parameters were obtained and summarized in Table 1 . It was seen that the smaller $R_{3}$ was also observed in $\mathrm{ZnO}$ nanocrystal electrode,

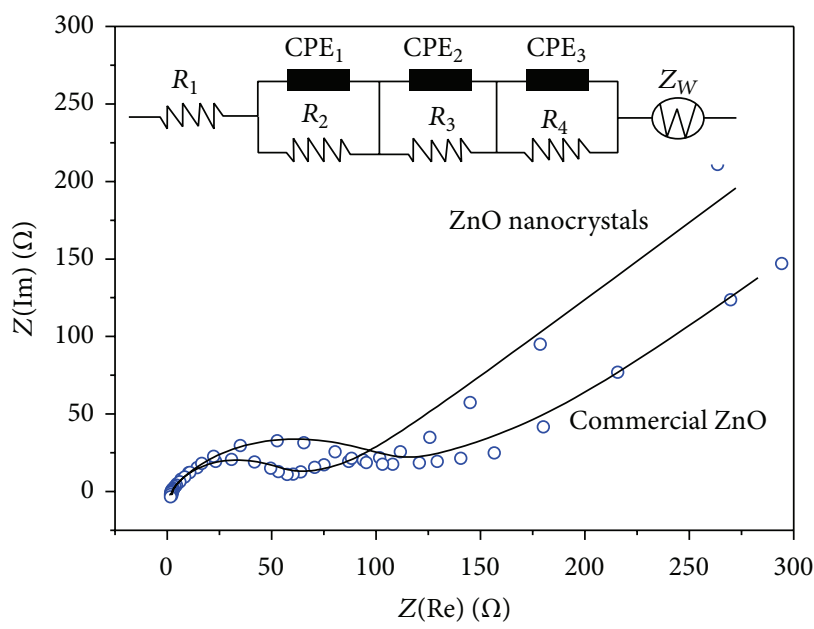

FIGURE 7: Nyquist plots for $\mathrm{ZnO}$ nanocrystal and commercial $\mathrm{ZnO}$ nanoparticle electrodes. The spots correspond to the experimental data, and the solid lines stand for the calculated data from the equivalent circuits of inset.

which usually favored the fast transport of $\mathrm{Li}^{+}$ions and the electrons across the interface. It also indicated that the carbon layer supplied fast charge-transfer channels on the interface of $\mathrm{ZnO}$ nanocrystal. $Y_{0,1}, Y_{0,2}$, and $Y_{0,3}$ of the $\mathrm{ZnO}$ nanocrystal electrode were higher than those of commercial $\mathrm{ZnO}$ electrode. The increase of $Y_{0,3}$ representing the electric double-layer capacitance favored the charge transfer for the 
electrode reaction. And the increase of $Y_{0,1}$ and $Y_{0,2}$ favored the diffusion of $\mathrm{Li}^{+}$in the SEI film and within the pore channels in the electrode, respectively.

$\mathrm{ZnO}$ nanocrystal electrode showed a smaller chargetransfer resistance and higher electric double-layer capacitance as compared with the commercial $\mathrm{ZnO}$ electrode, indicating an improved kinetic character of electrode reactions (i.e., charge transfer and polarization) which could be ascribed to the better availability of electrons and perhaps also $\mathrm{Li}^{+}$. The smaller particle size and better crystal type constituted a fast pathway for mass transport and electron transfer and hence improved Li storage capacity. The excellent capacity of the $\mathrm{ZnO}$ nanocrystals is highly attractive when compared with other reported $\mathrm{ZnO}$-based anode materials (Table 2).

\section{Conclusion}

In summary, $\mathrm{ZnO}$ nanocrystals with side-edge length of $10-15 \mathrm{~nm}$ were synthesized via the thermal decomposition method. A high reversible discharge capacity of $500 \mathrm{mAh} \mathrm{g}^{-1}$ of $\mathrm{ZnO}$ nanocrystals was observed after 100 cycles at $200 \mathrm{~mA} \mathrm{~g}^{-1}$. Compared with commercial $\mathrm{ZnO}$ nanoparticles, $\mathrm{ZnO}$ nanocrystals showed higher lithium storage capacity. These results are attributed to the structural difference of $\mathrm{ZnO}$ nanocrystals resulting in different cell impedance, which affects the Li-ion diffusion.

\section{Competing Interests}

The authors declare that there are no competing interests regarding the publication of this paper.

\section{Acknowledgments}

This study is supported by the National Natural Science Foundation of China (nos. 51402252 and 51541505) and the Natural Science Foundation of Jiangsu Province (no. BK20140463).

\section{References}

[1] A. K. Mondal, D. Su, S. Chen, A. Ung, H.-S. Kim, and G. Wang, "Mesoporous $\mathrm{MnCo}_{2} \mathrm{O}_{4}$ with a flake-like structure as advanced electrode materials for lithium-ion batteries and supercapacitors," Chemistry - A European Journal, vol. 21, no. 4, pp. 15261532, 2015.

[2] N. N. Wang, X. J. Ma, H. Y. Xu et al., "Porous $\mathrm{ZnMn}_{2} \mathrm{O}_{4}$ microspheres as a promising anode material for advanced lithiumion batteries," Nano Energy, vol. 6, pp. 193-199, 2014.

[3] W. Zhang, L. Yue, F. Zhang et al., "One-step in situ synthesis of ultrathin tungsten oxide@carbon nanowire webs as an anode material for high performance," Journal of Materials Chemistry A, vol. 3, no. 11, pp. 6102-6109, 2015.

[4] Y.Zhu, C. Cao, J. Zhang, and X. Xu, "Two-dimensional ultrathin $\mathrm{ZnCo}_{2} \mathrm{O}_{4}$ nanosheets: general formation and lithium storage application," Journal of Materials Chemistry A, vol. 3, no. 18, pp. 9556-9564, 2015.

[5] C. F. Pan, R. M. Yu, S. M. Niu, G. Zhu, and Z. L. Wang, "Piezotronic effect on the sensitivity and signal level of schottky contacted proactive micro/nanowire nanosensors," ACS Nano, vol. 7, no. 2, pp. 1803-1810, 2013.

[6] Y.-H. Tan, K. Yu, J.-Z. Li, H. Fu, and Z.-Q. Zhu, "MoS $@ \mathrm{ZnO}$ nano-heterojunctions with enhanced photocatalysis and field emission properties," Journal of Applied Physics, vol. 116, no. 6, Article ID 064305, 2014.

[7] Y. D. Zhu, Y. Y. Wang, G. T. Duan et al., "In situ growth of porous $\mathrm{ZnO}$ nanosheet-built network film as high-performance gas sensor," Sensors and Actuators B: Chemical, vol. 221, Article ID 18692, pp. 350-356, 2015.

[8] L. X. Song, P. F. Du, J. Xiong, F. Ko, and C. Cui, "Efficiency enhancement of dye-sensitized solar cells by optimization of electrospun $\mathrm{ZnO}$ nanowire/nanoparticle hybrid photoanode and combined modification," Electrochimica Acta, vol. 163, pp. 330-337, 2015.

[9] Y. Wang, H. Fang, Y. Zheng, R. Ye, X. Tao, and J. Chen, “Controllable assembly of well-defined monodisperse Au nanoparticles on hierarchical $\mathrm{ZnO}$ microspheres for enhanced visible-lightdriven photocatalytic and antibacterial activity," Nanoscale, vol. 7, no. 45, pp. 19118-19128, 2015.

[10] Y. F. Yang, Y. Z. Jin, H. P. He et al., "Dopant-induced shape evolution of colloidal nanocrystals: the case of zinc oxide," Journal of the American Chemical Society, vol. 132, no. 38, pp. 1338113394, 2010.

[11] L. Nasi, D. Calestani, F. Fabbri et al., "Mesoporous single-crystal $\mathrm{ZnO}$ nanobelts: supported preparation and patterning," Nanoscale, vol. 5, no. 3, pp. 1060-1066, 2013.

[12] Y.-J. Wu, C.-H. Liao, C.-Y. Hsieh et al., "Local electronic structures and polarity of $\mathrm{ZnO}$ nanorods grown on GaN substrates," Journal of Physical Chemistry C, vol. 119, no. 9, pp. 5122-5128, 2015.

[13] A. Umar, M. S. Akhtar, M. S. Al-Assiri et al., "Highly porous $\mathrm{ZnO}$ nanosheets self-assembled in rosette-like morphologies for dye-sensitized solar cell application," New Journal of Chemistry, vol. 39, no. 10, pp. 7961-7970, 2015.

[14] Q. Pan, L. Qin, J. Liu, and H. Wang, "Flower-like ZnO-NiOC films with high reversible capacity and rate capability for lithium-ion batteries," Electrochimica Acta, vol. 55, no. 20, pp. 5780-5785, 2010.

[15] X. H. Huang, X. H. Xia, Y. F. Yuan, and F. Zhou, "Porous ZnO nanosheets grown on copper substrates as anodes for lithium ion batteries," Electrochimica Acta, vol. 56, no. 14, pp. 49604965, 2011.

[16] X. H. Huang, J. B. Wu, Y. Lin, and R. Q. Guo, “ZnO microrod arrays grown on copper substrates as anode materials for lithium ion batteries," International Journal of Electrochemical Science, vol. 7, no. 8, pp. 6611-6621, 2012.

[17] X. H. Huang, R. Q. Guo, J. B. Wu, and P. Zhang, "Mesoporous $\mathrm{ZnO}$ nanosheets for lithium ion batteries," Materials Letters, vol. 122, pp. 82-85, 2014.

[18] L. F. Zhang, J. Z. Zhang, Y. Liu, P. Zheng, X. Y. Yuan, and S. W. Guo, "Al doped-ZnO nanoparticles implanted in reduced graphene oxide with improved electrochemical properties for lithium ion batteries," Materials Letters, vol. 165, pp. 165-168, 2016.

[19] X. Shen, D. Mu, S. Chen, R. Huang, and F. Wu, "Electrospun composite of $\mathrm{ZnO} / \mathrm{Cu}$ nanocrystals-implanted carbon fibers as an anode material with high rate capability for lithium ion batteries," Journal of Materials Chemistry A, vol. 2, no. 12, pp. 4309-4315, 2014.

[20] M. S. Song, S. Nahm, W. I. Cho, and C. Lee, "Enhanced electrochemical performance of a $\mathrm{ZnO}-\mathrm{MnO}$ composite as an anode 
material for lithium ion batteries," Physical Chemistry Chemical Physics, vol. 17, no. 36, pp. 23496-23502, 2015.

[21] Y. Zhao, X. Li, L. Dong et al., "Electrospun $\mathrm{SnO}_{2}-\mathrm{ZnO}$ nanofibers with improved electrochemical performance as anode materials for lithium-ion batteries," International Journal of Hydrogen Energy, vol. 40, no. 41, pp. 14338-14344, 2015.

[22] C. Y. Zhang, J. Dai, P. G. Zhang et al., "Porous $\mathrm{Fe}_{2} \mathrm{O}_{3} / \mathrm{ZnO}$ composite derived from MOFs as an anode material for lithium ion batteries," Ceramics International, vol. 42, no. 1, pp. 1044-1049, 2016.

[23] Y. Xiao and M. Cao, "Dual hybrid strategy towards achieving high capacity and long-life lithium storage of $\mathrm{ZnO}$," Journal of Power Sources, vol. 305, pp. 1-9, 2016.

[24] G. Zhang, S. Hou, H. Zhang et al., "High-performance and ultra-stable lithium-ion batteries based on MOF-derived $\mathrm{ZnO} @ \mathrm{ZnO}$ quantum dots/C core-shell nanorod arrays on a carbon cloth anode," Advanced Materials, vol. 27, no. 14, pp. 2400-2405, 2015.

[25] X. Sun, C. Zhou, M. Xie et al., "Synthesis of ZnO quantum dot/ graphene nanocomposites by atomic layer deposition with high lithium storage capacity," Journal of Materials Chemistry A, vol. 2, no. 20, pp. 7319-7326, 2014.

[26] C.-T. Hsieh, C.-Y. Lin, Y.-F. Chen, and J.-S. Lin, "Synthesis of $\mathrm{ZnO@Graphene} \mathrm{composites} \mathrm{as} \mathrm{anode} \mathrm{materials} \mathrm{for} \mathrm{lithium} \mathrm{ion}$ batteries," Electrochimica Acta, vol. 111, pp. 359-365, 2013.

[27] H. Wang, Q. Pan, Y. Cheng, J. Zhao, and G. Yin, "Evaluation of $\mathrm{ZnO}$ nanorod arrays with dandelion-like morphology as negative electrodes for lithium-ion batteries," Electrochimica Acta, vol. 54, no. 10, pp. 2851-2855, 2009.

[28] G. Yuan, G. Wang, H. Wang, and J. Bai, "Synthesis and electrochemical investigation of radial $\mathrm{ZnO}$ microparticles as anode materials for lithium-ion batteries," Ionics, vol. 21, no. 2, pp. 365371, 2015.

[29] J. Wang, N. Du, H. Zhang, J. Yu, and D. Yang, "Layer-by-layer assembly synthesis of $\mathrm{ZnO} / \mathrm{SnO} 2$ composite nanowire arrays as high-performance anode for lithium-ion batteries," Materials Research Bulletin, vol. 46, no. 12, pp. 2378-2384, 2011.

[30] V. Cauda, D. Pugliese, N. Garino et al., "Multi-functional energy conversion and storage electrodes using flower-like Zinc oxide nanostructures," Energy, vol. 65, pp. 639-646, 2014.

[31] Z. Wu, L. Qin, and Q. Pan, "Fabrication and electrochemical behavior of flower-like $\mathrm{ZnO}-\mathrm{CoO}-\mathrm{C}$ nanowall arrays as anodes for lithium-ion batteries," Journal of Alloys and Compounds, vol. 509, no. 37, pp. 9207-9213, 2011.

[32] M. Ahmad, S. Yingying, H. Sun, W. C. Shen, and J. Zhu, " $\mathrm{SnO}_{2} /$ $\mathrm{ZnO}$ composite structure for the lithium-ion battery electrode," Journal of Solid State Chemistry, vol. 196, pp. 326-331, 2012.

[33] M. Ahmad, S. Yingying, A. Nisar et al., "Synthesis of hierarchical flower-like $\mathrm{ZnO}$ nanostructures and their functionalization by $\mathrm{Au}$ nanoparticles for improved photocatalytic and high performance Li-ion battery anodes," Journal of Materials Chemistry, vol. 21, no. 21, pp. 7723-7729, 2011.

[34] H. Li, Y. Wei, Y. Zhao et al., "Simple one-pot synthesis of hexagonal $\mathrm{ZnO}$ nanoplates as anode material for lithium-ion batteries," Journal of Nanomaterials, vol. 2016, Article ID 4675960, 6 pages, 2016.

[35] F. Li, L. L. Yang, G. Xu et al., "Hydrothermal self-assembly of hierarchical flower-like $\mathrm{ZnO}$ nanospheres with nanosheets and their application in Li-ion batteries," Journal of Alloys and Compounds, vol. 577, pp. 663-668, 2013.
[36] H.-J. Yang, S.-C. Lim, S.-Y. He, and H.-Y. Tuan, "Ultralong mesoporous $\mathrm{ZnO}$ nanowires grown via room temperature selfassembly of $\mathrm{ZnO}$ nanoparticles for enhanced reversible storage in lithium ion batteries," RSC Advances, vol. 5, no. 42, pp. 3339233399, 2015.

[37] L. Yue, W. Zhang, W. Zhang et al., "One-step solvothermal process of $\mathrm{In}_{2} \mathrm{O}_{3} / \mathrm{C}$ nanosheet composite with double phases as high-performance lithium-ion battery anode," Electrochimica Acta, vol. 160, pp. 123-130, 2015.

[38] W. Zhang, L. Wu, L. Du et al., "Layer-by-layer assembly modification to prepare firmly bonded $\mathrm{Si}$-graphene composites for high-performance anodes," RSC Advances, vol. 6, no. 6, pp. 4835-4842, 2016. 

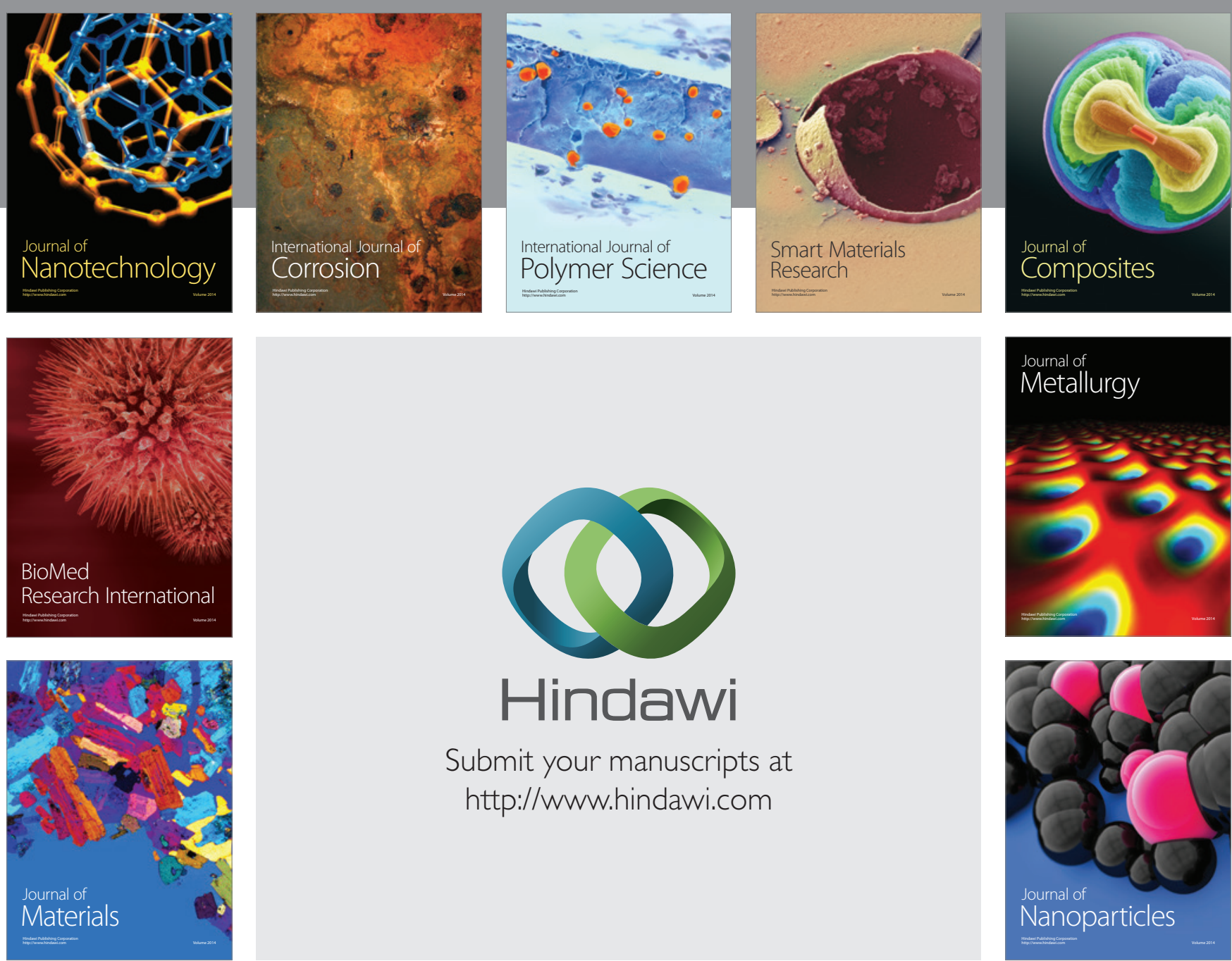

\section{Hindawi}

Submit your manuscripts at

http://www.hindawi.com

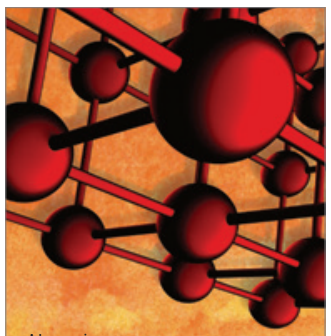

Materials Science and Engineering
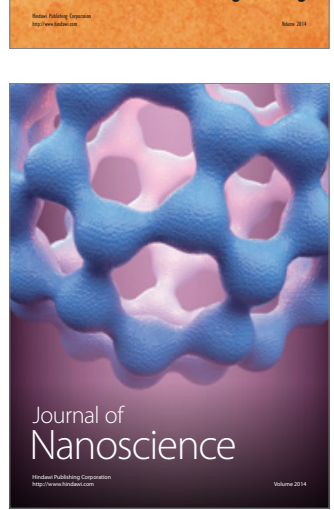
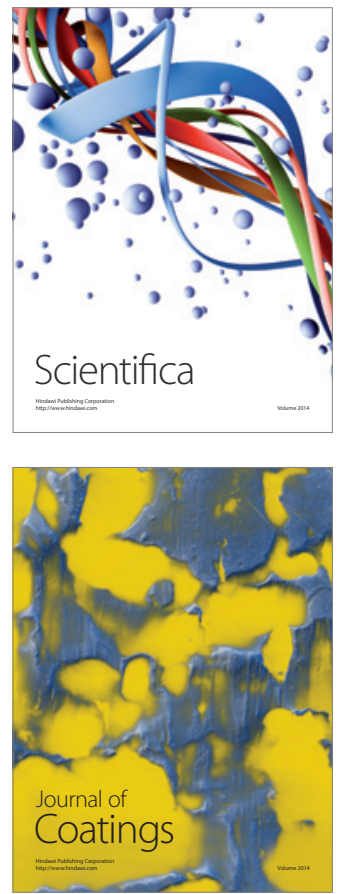
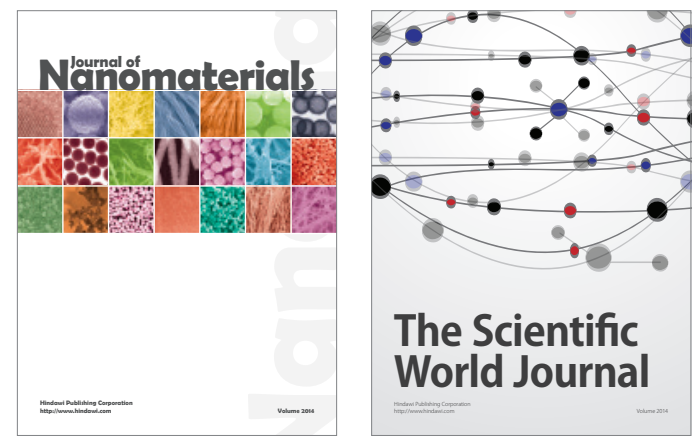

The Scientific World Journal
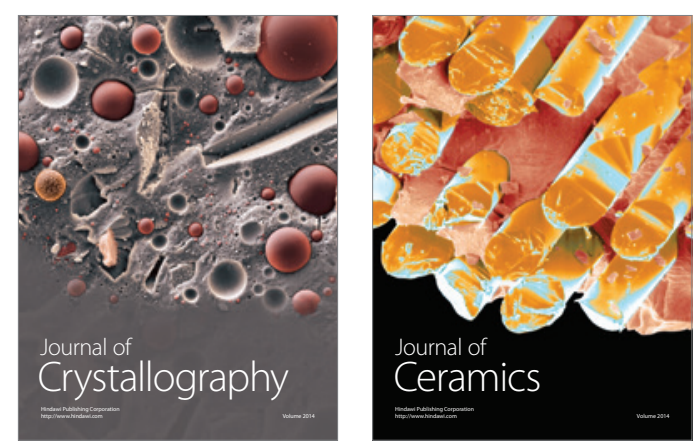
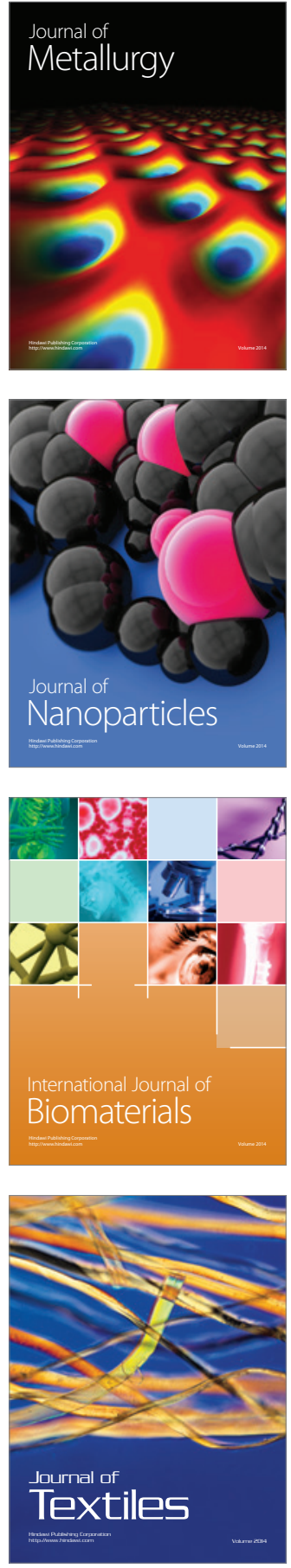